\title{
Recycling as an Inspiration for Architecture
}

AUTHOR:

\section{Matúš Kiaček ${ }^{1^{*}}$ \\ ${ }^{1}$ Alumni, Slovak University of Technology in Bratislava, Faculty of Architecture and Design, Institute of Architecture of Residential Buildings, Slovakia}

\section{*CORRESPONDING AUTHOR}

E-mail: matus.kiacek@gmail.com

\section{ARTICLE INFO}

Sent: Apr 23, 2021

Accepted: Jun 8, 2021

\begin{abstract}
The article approaches the inspiration of recycling at different levels of understanding. The introduction describes the meanings of the word recycling as it is perceived in relation to architecture. The first chapter approaches recycling through its most common understanding as material reuse, describing how the recycling of materials can inspire architecture. The second chapter takes up recycling in the sense of conversion, pointing out the particular importance of addressing this issue. The chapter mentions four theories dealing with approaches to conversion, which are specified through examples, and points to architectural recycling motivated by idea and by religion. The third chapter discusses architecture is inspired by recycling or reusing architectural elements that become the bearer of the idea of behind a new architectural concept. The fourth chapter reflects on understanding the recycling of architecture as taking on the formal image of historical architectural styles, thus reflected in the historical styles of the 19th century and postmodernism of the 20th century. The fifth chapter "Recycling the idea" seeks recycling at the level of the idea, by incorporating old ideas into modern concepts, referring to the Ideal City of Chaux and to Ricardo Bofill, the motif of the medieval mázhaus and Socrates' house. In the sixth chapter, entitled "Recycling as a concept", we read about inspiring architecture that takes on recycling at many levels of meaning, becoming important for objectifying the ideological essence of the work. The conclusion of the paper briefly summarizes the results of the work and its essence, summarizing a subjective evaluation of the issue.
\end{abstract}

\section{KEYWORDS:}

recycling, conversion, reuse, sustainability, ideational, values, preservation

\section{INTRODUCTION}

Recycling as an inspiration for architecture manifests itself at several levels of understanding and implementation, such as recycling of building materials, of functions or conversion, of structural elements, of form or historicism, and of ideas or adoption of an older concept, but today even in common energy recycling as recuperation - all based on the very meaning of the word recycling, and its multiple meanings. Recycling can mean going through a series of changes and modifications, in terms of the process of material recovery, or biological or chemical conversion to reuse a substance such as converting ADP to ATP (see note at the end of the introduction) or vegetation's recycling of biological residues in soil. However, recycling can also refer to adaptation for a new use, to transformation, for example in the form of a building's conversion. It also has the meaning of reuse and return, even in the abstract, such as recycling a concept or idea, or linguistic and literary or poetic media. Recycling also represents a certain repair, a preparation for reuse, such as reconstruction of a building. In the area of finance, recycling money is investing in areas that promise a certain return. Another interpretation of recycling is returning to a specific point in a cycle. The dictionary also interprets recycling as restoring to the original state, restoring an image, or resetting a program. Lastly, recycling can be the process by which usable material is obtained from waste for human production, for example in production of building materials. [1]

In general, recycling is considered to be: "the process of processing used objects or materials so that they can be reused" (Della Summers). [2] Summers' definition of recycling supports understanding it in architecture at several levels, through the reuse of material, elements, the building itself, and form and idea. For ecologically, culturally, and socially sustainable architecture, all the mentioned levels of recycling are necessary and equally inspiring.

Note: Adenosine triphosphate (ATP) is an energy transport molecule which, when one of the phosphate groups is broken off - during hydrolysis - turns to Adenosine Diphosphate 
$(A D P)$, releasing energy. This energy is then used in cellular processes and is the principle of energy metabolism.

\section{RECYCLING OF MATERIAL}

\section{Material cycles}

The direct impact of architecture, specifically of the building industry, is construction waste production. Closed and open material cycles are distinguished depending on whether or not it is reused. [3]

With a closed material cycle, the energy invested in the building, e g. in the form of material, is not lost after it had gone, but is reused through recycling: by recycling the building, i.e. by revitalizing it, or by dismantling it into recyclable elements and materials that will be used in new construction. The closed cycle inspired McDonough and Braungart to establish the Cradle to Cradle design model, based on a system similar to a natural ecosystem with an endless cycle and no waste. [4]

The open material cycle is unecological, wasting energy that is quite lost. After the building's useful service, it is demolished and the energy invested in it is not returned, leaving only unrecyclable waste, for the removal of which additional energy must be expended. On the site of the razed building a new one rises, again requiring expenditure of energy from the beginning, i.e. in mining, processing, and transport of material and the construction process.

\section{Historical examples of building material recycling}

Recycling of building materials has accompanied architecture throughout its development and long history. Not until the twentieth century was it rejected it with contempt, regarded as unworthy as a source of progress. However, past practice shows us that such rejection has become a pernicious aspect of architecture. It is all the more important to "step backwards", and not only reuse building material but return to certain values that go hand in hand with it. To return to ecological, architectural, cultural and social values. Using older material, we not only reduce the construction industry's ecological footprint, but we also pay respect to the generations through whose hands it passed, and perhaps respect to ourselves too.

There are illustrative historical examples of recycling of building materials in original ancient cities like Rome. Many of its former ancient monuments were gradually dismantled and their material reused, especially stone, for construction of medieval, Renaissance and Baroque buildings. The ancient ruins literally became an urban quarry. Relatively well-preserved buildings had a similar fate, such as the renowned Flavian Amphitheatre. Even though now we consider such dismantling of the ancient city controversial, it is inspiring for today's ecologically oriented architecture, as it conserves natural resources, energy, transport and human labour.

The continuous development of European cities is also reflected through recycling the buildings themselves - by conversion. From the contemporary point of view, we would perceive many of these conversions as relatively drastic, even devaluing of original architecture by negating its architectural or urban essence, as with Diocletian's Palace in Split. On the other hand, the medieval reconstruction of the Roman amphitheatre in Arles, while adding of medieval houses, retained the dominance of space and shape in the environment, today dominating it once more.

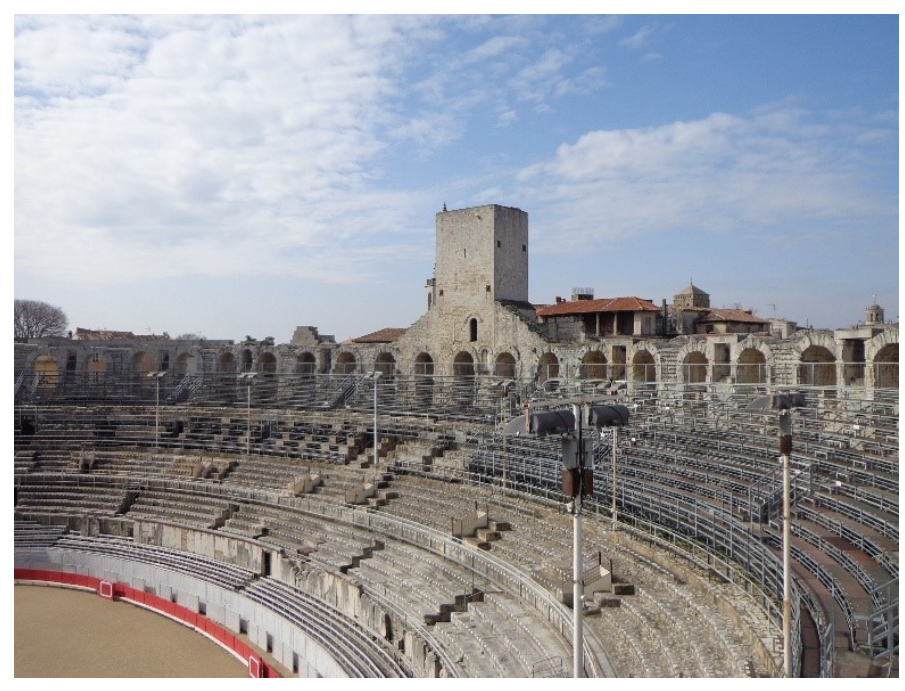

Figure 1: The ancient Roman amphitheatre in Arles, France, here in its current state, in medieval times retained its special composition despite added housing construction. Photo: Matúš Kiaček

\section{Current recycling of building materials in architecture}

Contemporary architecture is once again becoming interested in recycling building materials, especially for cultural values and ideational motives. The ideational reasons may include the intentional connection of the proposed building with the historical one, by appropriating its material. The material takes on the architecture's properties, which are then transferred to the new architecture through recycling.

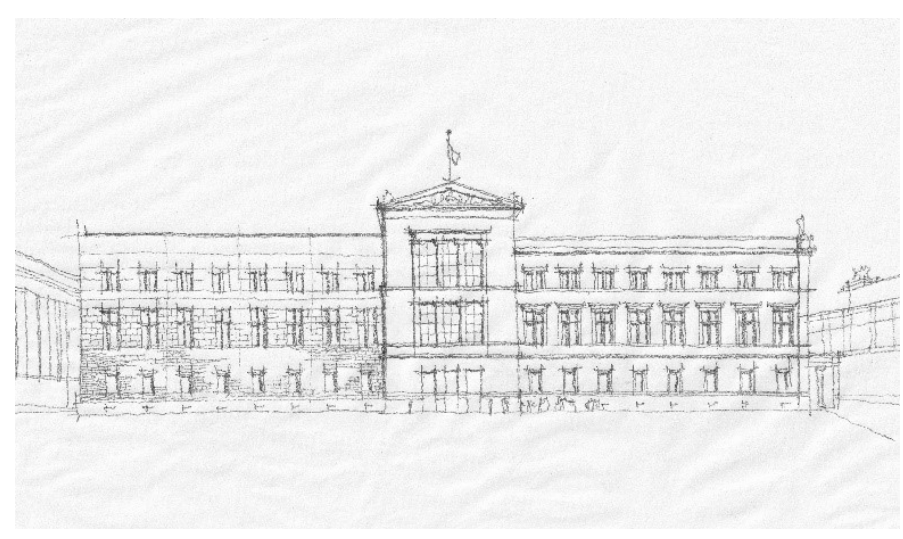

Figure 2: Reconstruction of Neues Museum in Berlin, left wing newly built of recycled bricks by David Chipperfield. Sketch: Matúš Kiaček

Unplastered brick is part of architectural history, and has undergone much technological development. However, over time many buildings built of it ceased to be used and became dilapidated. Recently there has been a growing interest in their revitalization, as well as the recycling of the bricks themselves. If it is no longer worthwhile to renovate the building, it is possible to 
recycle its bricks as material. Contemporary architecture built of it thus partially transfers the legacy of the previous architecture, or what it could represent. Additionally, it affirms the development continuum, and contributes to cultural and ecological sustainability.

Recycled old brick is increasingly inspiring for new buildings, such as the inconspicuous family house in Poznan, Poland by Wrzeszcz Architekci. The architects drew on the local rural context of dense forests and agrarian landscapes with remnants of German barns with brick facades once typical of the region. Brick facades with precise architectural details and balanced proportions give these barns their distinctive character in the area. The architects incorporated them directly into their design. They dismantled a nearby barn and used its bricks to build a new family house. "This became the key idea, which brought about significant change in the design approach in the field of architecture and sustainability," notes Wrzeszcz Architekci. [5] The architects believe that old architecture should not only be inspiring or discussed, but can be incorporated into contemporary architecture by recycling its material. The historical material gives the architecture and the place a special atmosphere and preserves its continuum. Quality craftsmanship finds its way to traditional masonry and confirms the legitimacy of the work. "Recycled bricks from an abandoned building give it a new life and add architectural qualities to the new building." [6]

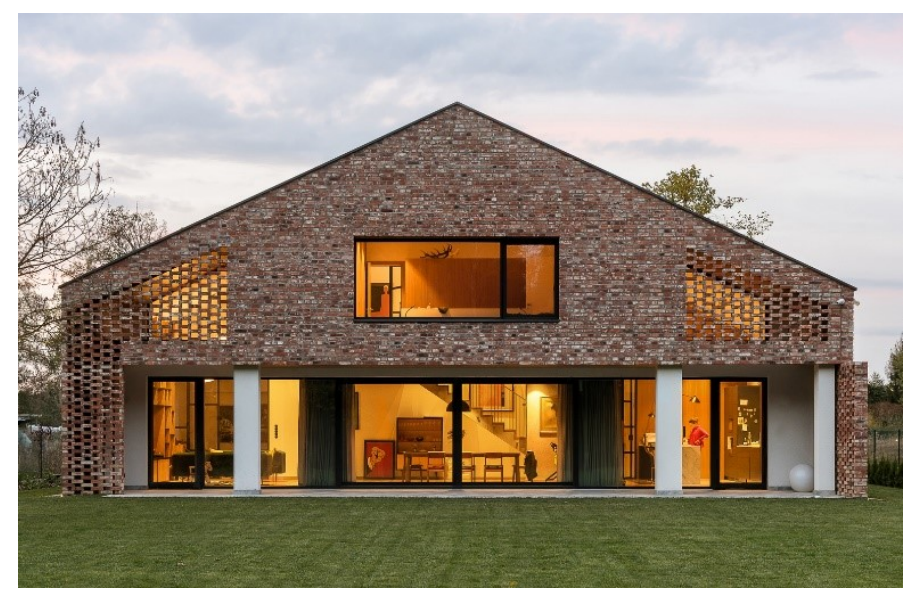

Figure 3: Old Brick New House in Poznan, Poland, recycled brick with the volume composition of local German barn by Wrzeszcz Architekci.

Photo: Przemyslaw Turlej. Source: [5]

Among ceramic materials, fired tiles are relatively easy to recycle, with simpler disassembly and no need to clean off mortar. It appears mainly in Asia in the work of Wang Shu, and in European "terracotta" countries, e.g. in the work of Arthur Franco in Spain. The reconstruction of the $8 \mathrm{~B}$ Nave converted a former slaughterhouse using construction waste from its site. From disassembled tiles he created interior walls and dividing structures of various degrees of transparency. "This project seeks to understand architecture as an intellectual, cultural and ethical experience." [7]

Concrete is currently the most commonly used building material, thanks to its unique properties of strength, durability, versatility and adaptability, accessibility, easy handling and, last but not least, aesthetics. However, at the same time it is the most environmentally taxing, largely because of its production, which produces eight percent of the world's carbon dioxide pollution. In combination with steel reinforcement it is rigid and difficult to take apart and recycle. Nevertheless, reinforced monolithic concrete is recyclable, "dismantlable" using a special technique of cutting into blocks or slabs. Even cast steel reinforcements can be removed with special magnets and then recycled. However, the process is technologically demanding, expensive, and requires transport to a suitable workplace. In addition, recycling requires added use of cement and water and a lot of energy. The environmental friendliness of such recycling is therefore in many cases questionable. It is worthwhile when large amounts from one source is recycled, and when it is reused for less quality-demanding construction, such as roads. A more architecturally interesting inspiration is the use of crushed concrete, for instance in gabion form.

Due to its character and assigned atributes, stone is the noblest and most durable of materials. Durability could make it a potentially sustainable material, but the environmental impacts of quarrying, transporting and processing it are too great. Quarrying stone as was done in the past is now practically unsustainable, due to its intensity and volume. However, it is possible to recycle already stone that has already been quarried, from construction sites or from production residues. Another interesting and rediscovered method is processing it into terrazzo, which significantly reduces the quality requirements for the source stone. This can be seen in Neues Museum or in the Slovak National Gallery.

\section{RECYCLING AS CONVERSION AND ITS PRINCIPLES}

Sustainable development and the functioning of urban organisms are conditioned by effective management of the resources a city has, especially space and area, infrastructure and building stock, i.e. existing architecture. Compared to architecture currently under construction, it forms the majority of the city's building stock and therefore it deserves more attention. Most buildings are sufficiently flexible spatially and structurally and susceptible to new concepts, functions and expressions.

Is it not bitter irony when original architecture is demolished to build more environmentally and energetically acceptable architecture? Can any modern eco-architecture really be of benefit if preceded by such a waste of resources, energy and materials? Would not recycling original architecture be more environmentally sustainable, even if the building has higher energy costs?

In recent years, several conferences and studies have addressed building conversions. Different approaches are based on specific principles. Four of them are presented in a clear comparison in the Perić and Šijaković article Recycling Architecture: The Redefinition of Recycling Principles in the Context of Sustainable Architectural Design: [8] Intervention, Insertion, Installation (by Brooker \& Stone), Add-on, Inside-Out, Change Clothes (Feirreis \& Klanten), Addition, Transformation, Conversion (Jäger) and Coexistence, Imposition, Fusion (Rogić). 


\section{Intervention, insertion, installation}

The concept of "Intervention-Insertion-Installation" is based on the relationship between original architecture and a new architectural intervention. According to a structure's degree of constructional, spatial, and expressive dependence on the original one, recycling methods are divided among these three categories.

Intervention is characterized by transforming the original architecture but preserving its expressive, spatial, and structural dominance. Although the interventions are distinguishable and subordinate, they are an integral part of the whole image and thus there is a mutual dependence of old and new. One example is Museum Küppersmühle by Herzog \& de Meuron.

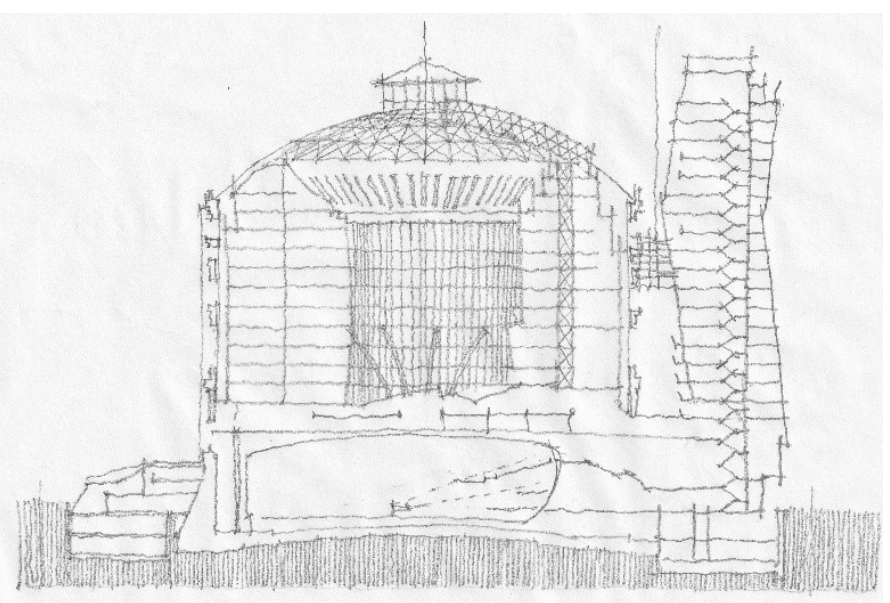

Figure 4: Gasometer in Vienna, Austria, inserted inner architecture maintaining the original architectural envelope by Coop Himmelblau. Sketch: Matúš Kiaček

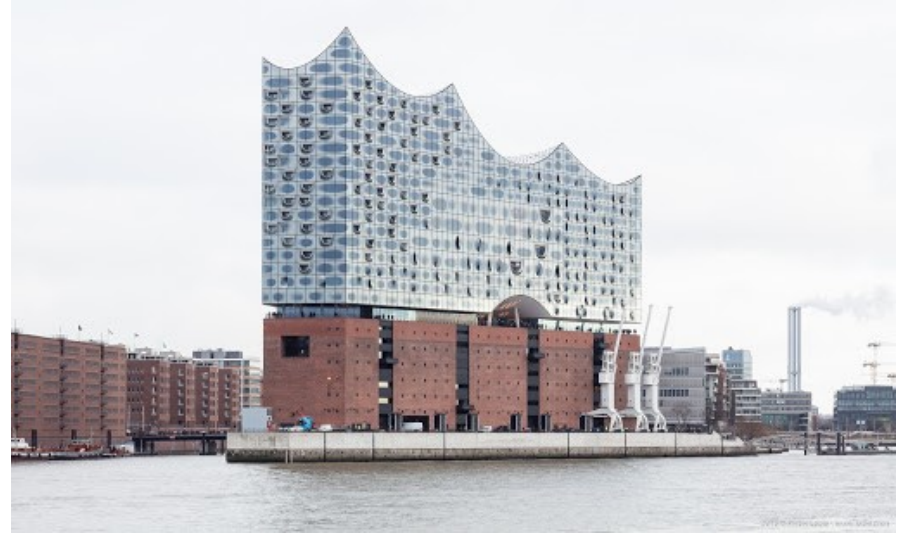

Figure 5: Elbphilharmonie in Hamburg, Germany, independent look and concept of installed superstructure by Herzog \& de Meuron. Photo: Sophie Wolter. Source: https://www.baunetzwissen.de/glas/objekte/kultur/elbphilharmonie-inhamburg-4962491

With insertion, a building accepts new elements, usually intended to adapt it to a new function while not significantly changing the original architecture's character. The more significant changes concern interior spaces, for example by inserting floors and other structures. Embedded elements often have a deliberately special form. The principle of insertion appears in interior reconstructions of historical buildings, preserving the external image and adapting the inner layout.

The principle of installation is similar to "insertion", but is accompanied by more drastic interventions, with contrasting new elements even changing the architecture's external appearance. An example is the Elbphilharmonie in Hamburg by Herzog \& de Meuron. The principles of "insertion" and "installation" are very similar, and their specific solutions cannot usually be strictly defined.

\section{Add-on, inside-out, change clothes}

Principles of architectural recycling according to the model of Feirreis \& Klanten's "Built-On converted architecture and transformation buildings", [9] which distinguishes three types of recycling, namely "Add-on, Inside-Out, Change Clothes" is based on the relationship between the original and the new structures.

Add-on is a broad category, ranging from projects that restore the original form of the architecture to projects that completely change its character. An interesting specimen is CaixaForum in Madrid by Herzog \& de Meuron. Although the superstructure's new architecture comes in with a different expressive and structural outlook and the original interiors are also changed significantly, the overall architectural image is gently harmonized and a holistic and spatial concept results.

Inside-out sometimes drastically changes the inner spatial composition but usually keeps the outer form intact. It is typical of the reconstruction of war-torn Berlin, such as the adaptation of Schinkel's armoury, Neue Wache, to a memorial with a statue of the Mother with her Dead Son by Käthe Kollwitz.

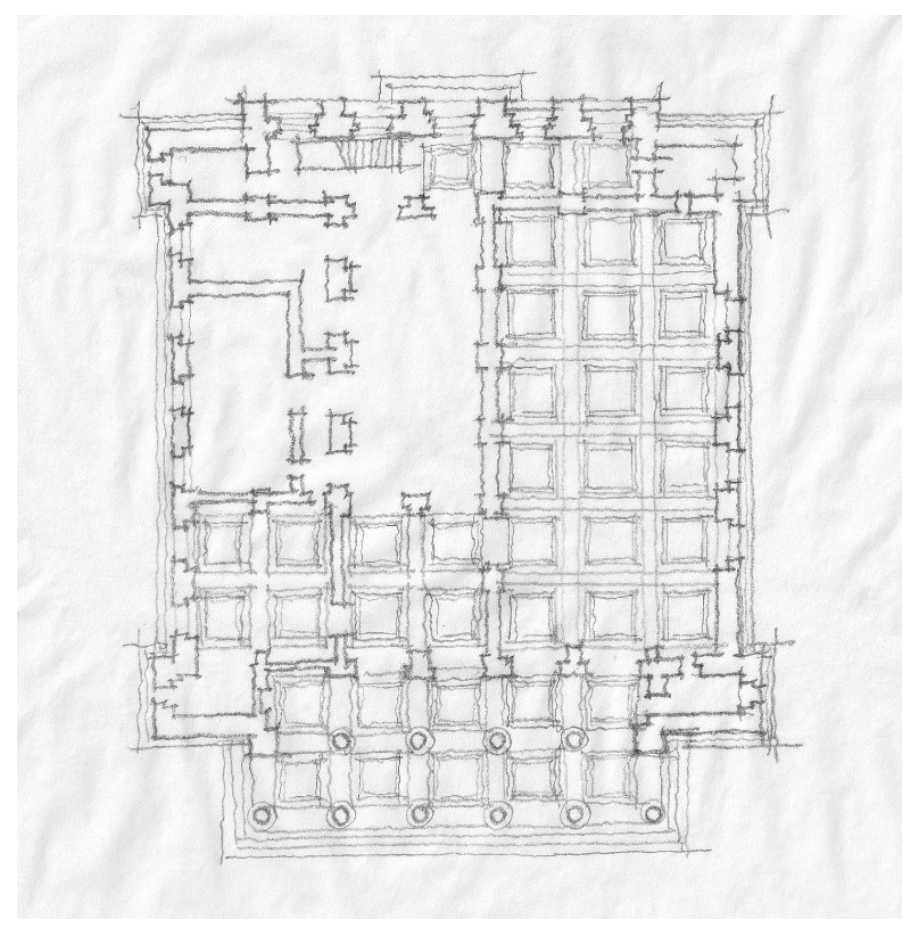

Figure 6: Neue Wache in Berlin, Germany, former interior scheme from the 19th century by Karl Friedrich Schinkel. Sketch: Matúš Kiaček 


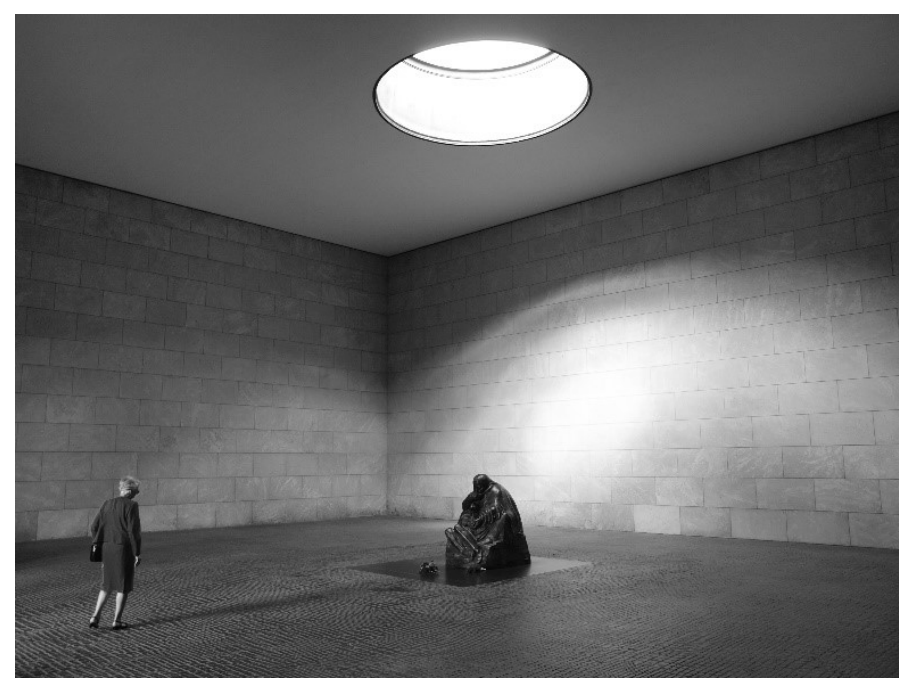

Figure 7: Neue Wache in Berlin, Germany, current state of interior, now as Central Memorial of the Federal Republic of Germany with the sculpture of Mother with her Dead Son by Käthe Kollwitz. Source: https://commons.wikimedia.org/wiki/File:Neue_Wache,_Berlin._In_mem oriam..JPG

The concept of "Change Clothes" is the most radical, as the new structure dominates, allowing itself to break the formal "order" of the original architecture, even to a large extent for the exterior. The danger of the concept is a risk of damaging the architecture's original values and erasing its historical and cultural legacy, when the new directly "devouring" the original architecture.

\section{Addition, transformation, conversion}

According to Jäger, the main principles of the categorization of "recycled architecture" are quality and maturity of the interventions. [10] In the addition principle, new architecture is inserted, being distinct, architecturally independent, yet submissive to the old, e.g. the glass café in the ruins of the Zeughaus by HansJoachim Neukäter. Transformation is more assertive than addition, blurring the structural and spatial boundaries between the new and the old, as Tadao Ando has done with Punta della Dogana. The new construction complements the old, and together they submit to the renewed space. Conversion cannot be considered as a third separate category. In fact, the whole categorization is based on very abstract criteria, and therefore difficult to specify.

\section{Coexistence, imposition, fusion}

Coexistence is based on the parallel existence of the new and the old, duly manifested by their structural and material distinction, as well as by their formal image. Imposition prefers new elements to the old, not much taking into consideration the original architecture. Fusion occurs when the original and new construction and material are seemingly indistinguishable, thus appearing as one architectural unit.

Branislava Rogič analysed the three principles on two levels, tectonic and spatial-compositional. She finally formulated four concepts: "Tectonic fusion", where new and old construction and material form one architecture; next what is referred to as "Tectonic coexistence", in which the structures and materials of the old and new architectures act independently; "Spatial com- position conservation", with the preservation of the original spatial concept and the intervention influenced by it; and finally "Spatial composition transformation" with a changed spatial composition. [11]

\section{Summary of recycling concepts as conversions}

"... it can be concluded that the most environmentally sustainable recycling intervention will be one which fully exploits the host building, inducing as minimal change as possible, given that the conditions of the host building allow it" (Perić, Šijaković). [12] From an ecological point of view, it can be said that the most efficient conversion is the one that preserves the original material and structures as much as possible, because it reduces the energy costs of production and construction work, though resulting in the building's higher energy efficiency.

\section{Religious and ideologically motivated conversion}

Hagia Sofia, the Temple of Holy Wisdom, in Constantinople, was converted into a mosque after the fall of the Eastern Roman Empire in 1453, characterized by the completion of four minarets and covering interior murals depicting Christian scenes by plaster. Despite the religious or ideological change the architecture did not undergo a significant change in composition, space, or overall expression.

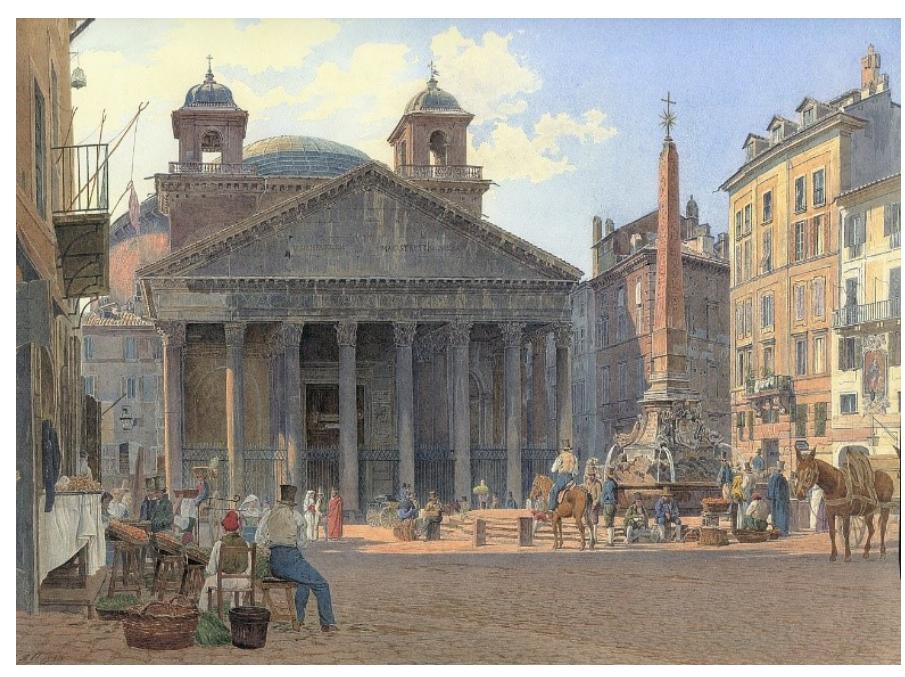

Figure 8: Ancient Roman Pantheon, Rome, with added bell towers from the 17th century, as a Christian church. Painting by Jakob Alt. Source: https://www.ArchDaily.com/802201/ad-classics-romanpantheon-emperor-hadrian

The opposite is the case of the former Great Mosque of Córdoba, Andalusia, which was quite drastically Christianized after the Christian victory in the Iberian Peninsula by building a church in the middle of an eighteen-nave space. Here, too, a religious conversion took place, but the composition of the original architecture changed significantly. Rather than recycling, it is a kind of objectification of ideological victory.

The Munich House of Art is an inspiring recycling of architecture. Designed by the architect Paul Ludwig Troost as the first Nazi German architecture, originally the House of German Art, it became a significant ideological tool of propaganda. While the building embodied imperial architecture, 
its exhibition presented the Nazi notion of art, legitimized by the corresponding dishonour of "degenerate" art - especially the avant-garde. Today the museum presents modern and contemporary art, with no permanent collection. The donated work "Joys of Yiddish" by the Jewish artist Mel Bochner is installed on the entablature of the front colonnade, as a memorial of the Hebrew words lost from German culture.

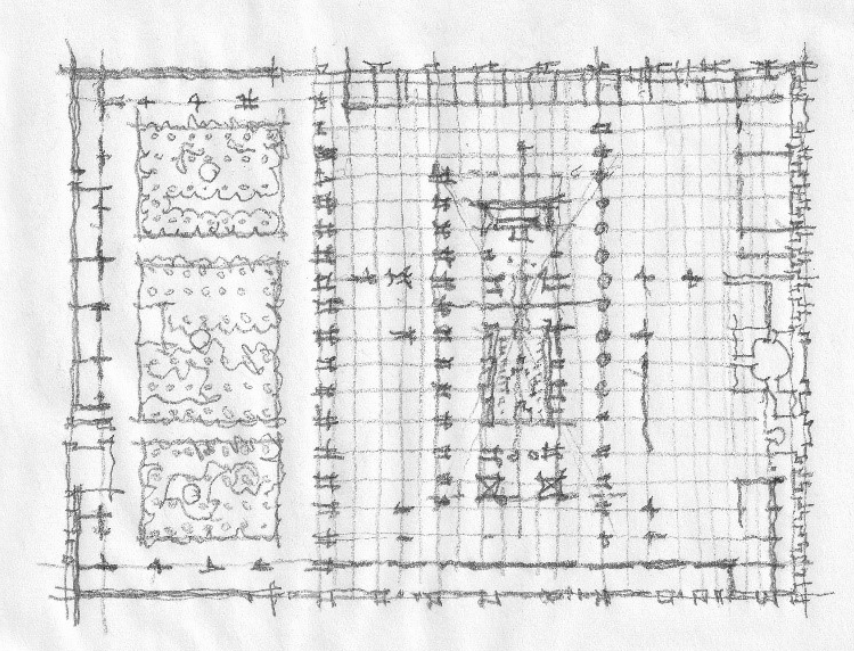

Figure 9: The Great Mosque of Córdoba, Spain, Christian Baroque church built in the 18-nave hall, changing the original spatial composition and volume. Sketch: Matúš Kiaček

\section{RECYCLING OF ELEMENTS AND PRODUCTS}

\section{Recycling of construction elements}

Recycling of building structures can be seen on the walls of Europe's medieval cities. When a city's fortification system lost its functional significance it was not only pulled down, but also often used for new construction. Both approaches can be seen in Bratislava. On one hand the southern walls were pulled down to establish free public space on Hviezdoslav Square, inspired by Vienna's Ring; on the other hand, new burgher houses and workshops were added on the northern and western walls.

It is also inspiring to recycle a smaller architectural element that is important for the concept. By its meaning, the recycled element can become the basic idea of a new architectural concept or a significant part of it. Most of these are elements whose value is in objectifying an important idea, memory, or religious idea, for instance when a new church is centred around an older preserved element, altar, baptistery, or tomb of a saint, or a chapel, bell tower, etc.

\section{Recycling of art elements}

A special category the recycling of artistic elements, as they primarily bear (among other things) artistic significance. Their re-installation is not only a reuse of an architectural element, but an artistic enrichment of new or even old architecture. An example is the modernist building of the Church of Saint Joan of Arc (1979) in Rouen, Normandy, by the architect Louis Arretche. Despite its modernist architecture, construction, material and form, the concept carries a strong idea in the form of installed Gothic stained glass windows from the war-ravaged church.

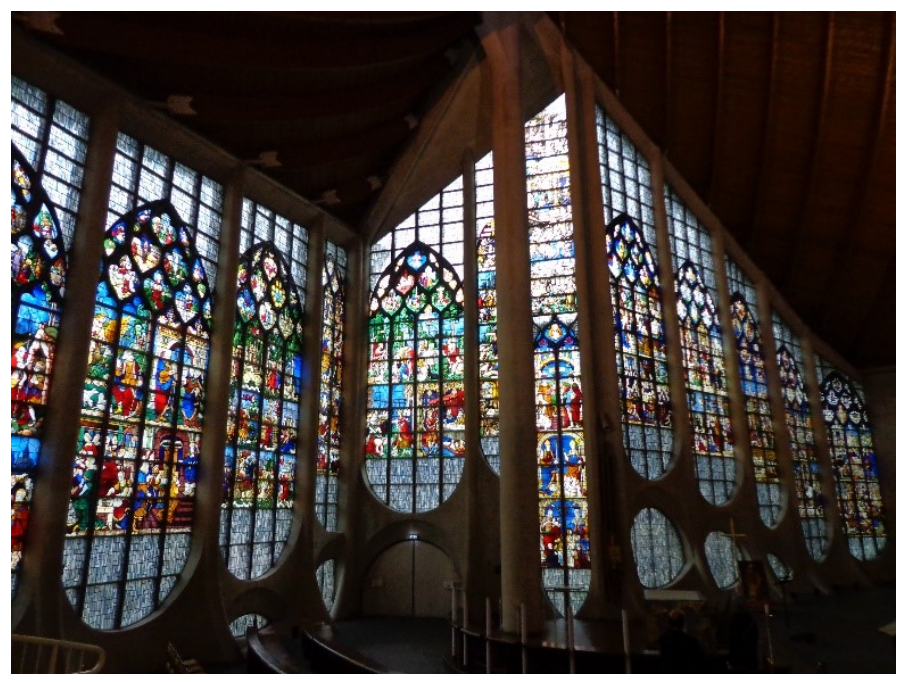

Figure 10: Church of Saint Joan of Arc, original Gothic stained glass windows as main idea of the new architectural concept by Louis Arretche. Photo: Matúš Kiaček

\section{FORM RECYCLING}

The historicist architectural styles of the nineteenth century clearly objectify the recycling of form. Historicist styles were not only inspired by the expression mediums of former styles, but also directly took on their stylistic architectural elements, compositional principles, and expression. Whether with the romantic neo-Gothic of the Feigler family, or other eclectic styles of the neo-Romanesque style or the neo-Renaissance and neoBaroque of Fellner and Helmer that architecturally and culturally unified the lands of the monarchy, or the architecture of Bratislava's Kittler and Gratzl, the old design was restored.

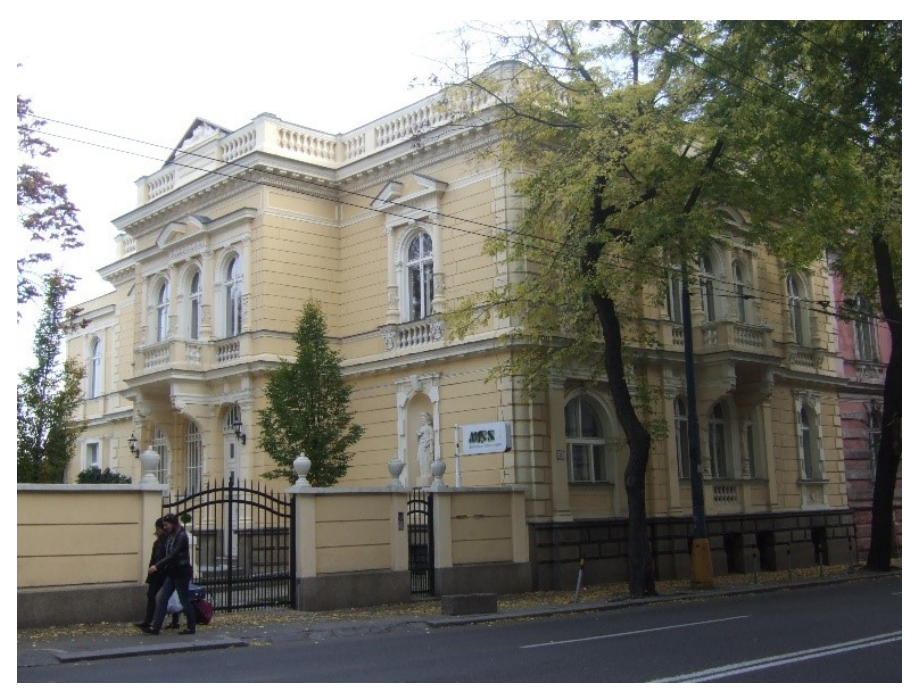

Figure 11: Eclectic villa, Bratislava, recycled Baroque and Renaissance architectural forms by Ferdinand Kittler and Karl Gratzl. Photo: Matúš Kiaček

Similarly, the postmodernism of the twentieth century restored historical styles but more vaguely, while still recycling the expressive essence, although often reinterpreted by non-standard 
shape variations, deformations, and combinations, as with Ricardo Bofill. Bofill takes on shapes and elements, but allows himself to double-break the broken pediment, erect a glass pillar, or break it in the middle of the shaft, as in the project Les Espaces d'Abraxas (1978).

Recycling of form is a suitable means applied by architects in modern interventions in the historical structure and reconstruction of older buildings. It is variously understood, from strict copies of the original form as in neo-styles, through modified imitations and stylizations, to slight references and abbreviations.

\section{RECYCLING THE IDEA}

Recycling of an idea is most common in architecture and art and in culture and society in general, and most diverse in extent and depth of expression. Recycling the concept and idea of a work is usually termed inspiration, but in essence it is a matter of reusing the idea and adapting it to new conditions. In the sense of returning to a certain point in the development cycle, the Renaissance goes back to classical antiquity, and its philosophy, social system, culture and art, recycling it. Compared to the neo-styles of the Long Century, the Renaissance was a renewal of the idea, the essence of the time. Similarly, Classicism restores not only the ancient image of architecture and art, but especially of thinking and, in France, the model of civil society. Despite seemingly formal copying, Classicist art, particularly painting and music, is innovative and very different from the ancient image.

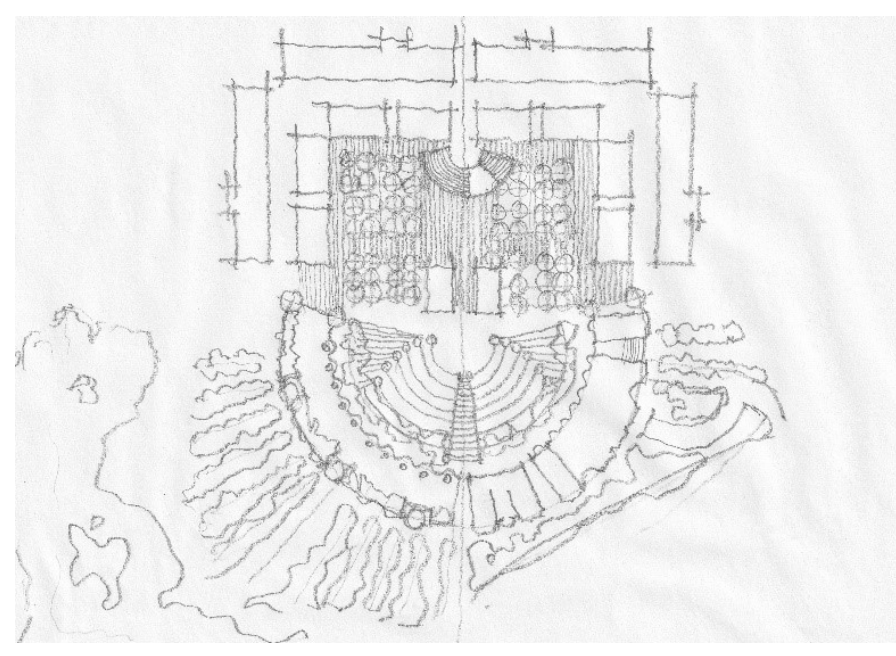

Figure 12: Palacio de Abraxas in Noisy-le-Grand, France, idea of ancient theatre transformed to a housing complex life as play by Ricardo Bofill. Sketch: Matúš Kiaček

Claude-Nicolas Ledoux was so inspired in the project of the Ideal City of Chaux (1795), or rather took over the concept of ancient theatre, although functionally the city was not related to any theatre. Similarly, Ricardo Bofill in Les Espaces d'Abraxas (1978) revives the Roman theatre, even though he is building apartment buildings. Otto von Spreckelsen, in turn, adopts the concept of the Arc de Triomphe and, in a modified form, designing the Grande Arche de la Fraternité (1989) as a symbol of the victory of the French Revolution and its bicentennial.
The recycling of the Socrates' house concept brought us the ecological and undemanding sustainable architecture of a detached house, similar to the zemlanka (underground shelter) idea or medieval town house model. Mázhaus is a sustainable concept of living and working in one place, saving on space and transport. In this case recycling can also be described to some extent as the renewal of a lifestyle, or at least partial return to it.

\section{RECYCLING AS A CONCEPT}

\section{Wang Shu}

Wang Shu's work and concepts are characterized by inspiration in traditional craftsmanship, genius loci, and the recycling of materials, as well as its craftsmanship in processing. He considers the recycling of materials to be a natural part of architecture, and a need of sustainable architecture in respecting the place as well as nature, but also culture and society in not flooding it with worthless waste. Recycling in Wang Shu's work also involves a significant rejuvenation of traditional Chinese architectural concepts and forms.

\section{Museum of History in Ningbo}

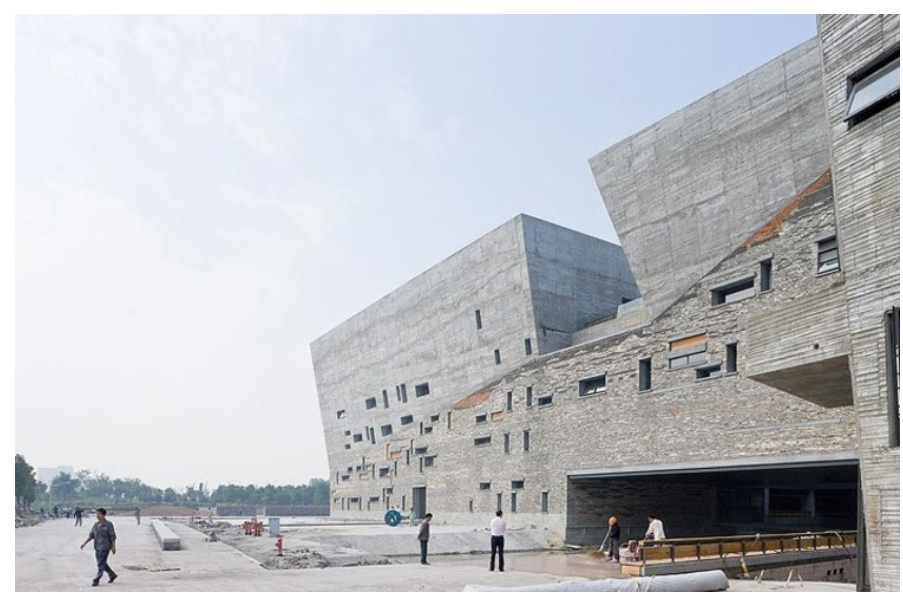

Figure 13: Museum of Ningbo, Ningbo, China, and the recycling of construction waste, craftsmanship, and the embodied idea of mountain as symbol of return to nature by Wang Shu.

Source: https://www.ArchDaily.com/942622/wang-shus-works-oncontemporary-chinese-architecture-with-recycled-materials

The museum is located in a developing part of Ningbo, where the former character of a port has completely disappeared due to the intense urban transformation. The concept is based on the idea of a mountain, a symbol of nature in Chinese culture, and its relationship to man, poetically returning tradition to this city. The facade supports the idea of the mountain: it consists of raw concrete and recycled construction waste from demolished local traditional architecture. It is made of waste such as bricks, terracotta tiles, stones, and concrete. The architecture of the museum inspires by recycling building material as well as conceptually recycling the tradition and identity of the place.

\section{David Chipperfield and Neues Museum}

The reconstruction of Neues Museum, originally designed by the architect Friedrich August Stüler (1841-1859) in the Classicist style, has several levels of recycling. "The key aims of the 
project were to recomplete the original volume, and to repair and restore the parts that remained after the destruction of World War II. The original sequence of rooms was restored with newly built sections that create continuity with the existing structure," notes David Chipperfield. [13] Compared to the reconstruction of the Reichstag by Norman Foster, Chipperfield leaves more visible traces of the war, in the form of recycling "marked" material and structural elements. According to the architect: "It was not about retaining the damage, it was about retaining the original material. Our approach was that no original material could be removed allied to the idea that the difference between the old and the new should only be perceptible in a second glance. This is how archaeological repair is done... There was a lot of rhetoric about us wanting to make a monument to war, but that was not at all the idea. We took a much more secular attitude toward the ruin: the important thing was the original material, which we refused to discard." [14]

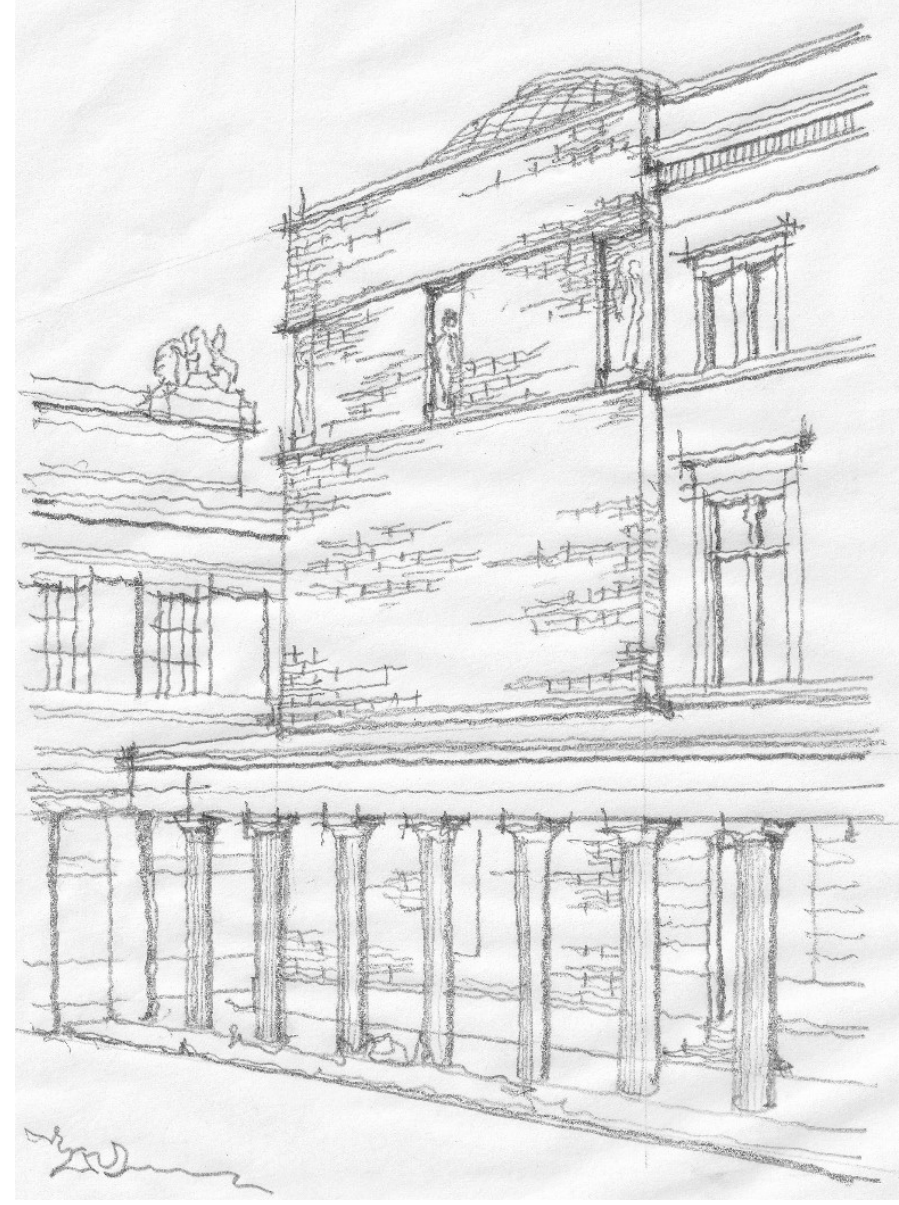

Figure 14: Reconstruction of Neues Museum in Berlin, the corner avant-corps newly built from recycled bricks by David Chipperfield. Sketch: Matúš Kiaček

The volumes of the north-western wing, with the Egyptian courtyard and the Apollo avant-corps, the apse of the Greek courtyard and the southern dome, are rebuilt from recycled hand-made bricks, continuously carrying on from the preserved parts. The walls contain original as well as new bricks, while their uneven colour, texture, and degree of weathering testify to the architecture's temporality. The restoration and addition of the southern and eastern colonnades restores the original urbanism, as completed by the James Simon Gallery.
The new exhibition spaces consist of large-format prefabricated concrete elements, containing white cement and fragments of Saxon marble from the museum's original tiles. The recycling of the original materials connects the museum with its own past; its reconstruction is primarily a recycling of the idea. That inspirational recycling manifests itself in the level of material, spatial creativity, ideology, and cultural and social significance.

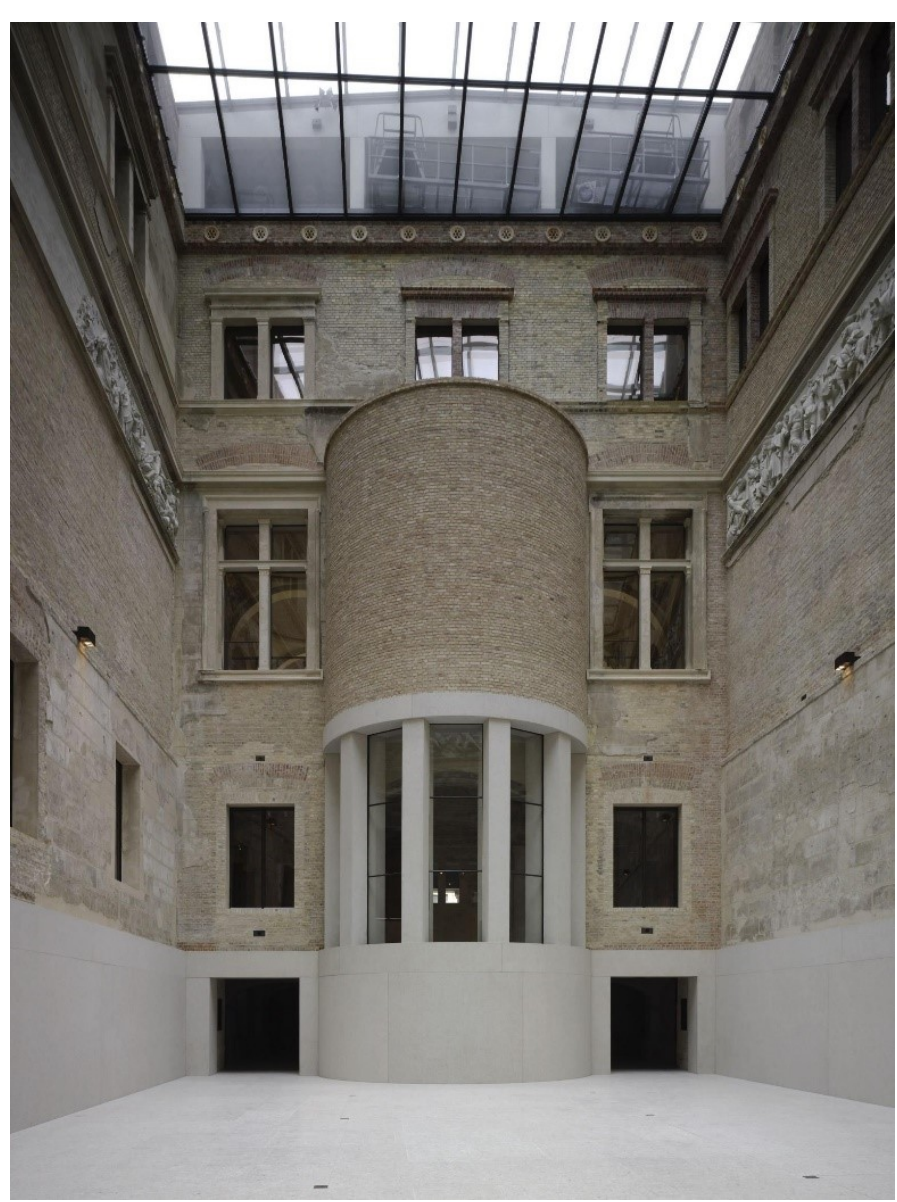

Figure 15: Reconstruction of Neues Museum in Berlin, Greek courtyard with white concrete prefabricates of original Saxon Marble by David Chipperfield.

Source: https://archello.com/en/project/neues-museum

\section{Studio BKPŠ Martin Kusý and Pavol Paňák}

\section{The Slovak National Gallery}

The reconstruction of the Slovak National Gallery is inspiring for its scope, approach, and ideational and material interconnection of architectural concepts. Its main motive is to recycle both embedded concepts and their design and material.

The original stone paving of the courtyard has been finely crushed into a covering the for the courtyard surface. Similarly, some unsatisfactory stone tiles and elements are being recycled and, as benches and installations, will become part of the limestone park. As a part of the reconstruction, refurbished original sheet metal tiles are also being used, and their recycling and reuse leave the building in contact with its past and support its authenticity. The tiles are also intentionally mixed and reused as cladding, giving the facade a new colour pattern, while keeping the original materiality. The northern barracks plaster facade is being stripped, and the hand-made brick ma- 
sonry rearranged by hand-worked stones testifies to the construction history of the building and the whole complex.

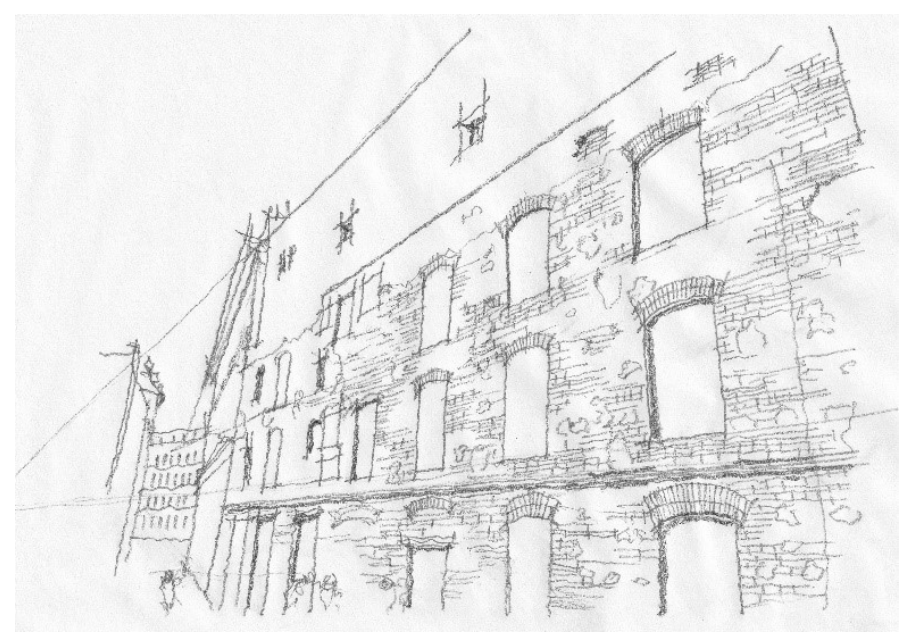

Figure 16: Reconstruction of the Slovak National Gallery in Bratislava, original Baroque masonry stripped of plaster, reflecting its construction history and inputs by BKPŠ. Sketch: Matúš Kiaček

Museum of the Slovak National Councils in Myjava

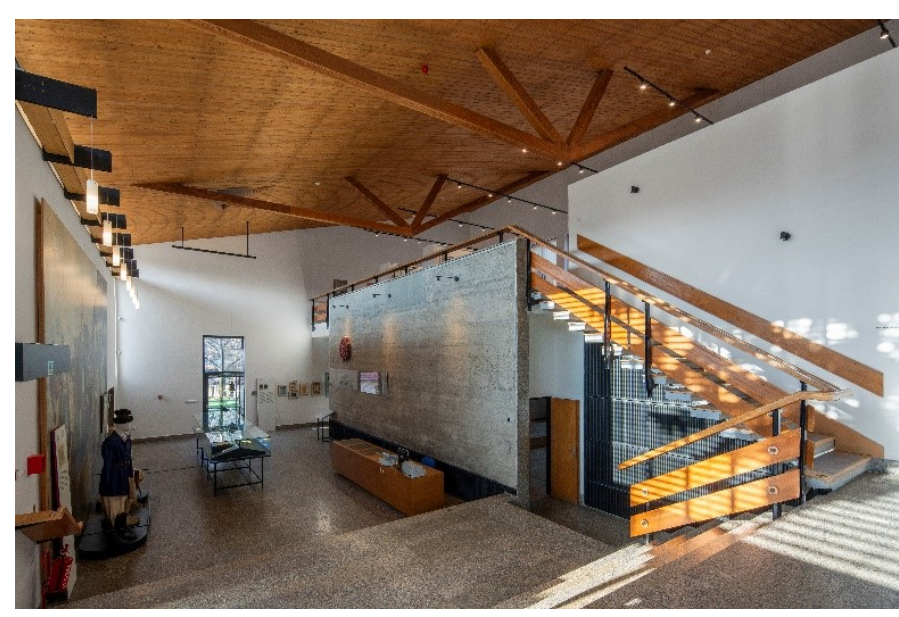

Figure 17: Reconstruction of Museum of Slovak National Councils in Myjava, with preserved interior, spatial concept and materiality by BKPŠ.

Source: https://www.archinfo.sk/diela/obcianska-stavba/rekonstrukciaarealu-muzea-slovenskych-narodnych-rad-v-myjave.html

The renovation of the complex of the Museum of the Slovak National Councils shows the possibility of recycling the original materials on-site and in an unchanged form. Rough plaster, exposed concrete, a brutalist interior wall and stone cladding, and wood panelling have all retained their original condition, requiring no intervention except minor repairs, "emphasizing preservation of the original atmosphere and materiality," states Henrieta Moravčíková. [15] Most inspiring is the relatively small intervention, to contribute to the recycling of architecture and its materiality and authenticity.

\section{CONCLUSION}

In conclusion, in this article the author has tried to show that recycling in architecture does consists not only of the technological process of processing waste material into reusable ma- terial in construction, as is commonly held, but comprises a much broader level of meaning. Recycling can be an inspiration for architecture not only through use of recycled material, but also by reprocessing architecture through converting it, by taking over forms or inspiring elements and, last but not least, taking over and developing an important and inspiring idea and processing it into a concept. The author holds that such a view of recycling in architecture, or even in art and culture in general, is far more inspiring and beneficial than a narrow focus on the issue of material processing, which is of rather secondary assistance in materializing an idea. The inspiration of recycling consists of the idea and belief in the importance and significance of preserving some values. These values are ecological as well as aesthetic, cultural, social and ideological in general. The author sees the inspiration of recycling in preserving values, in any interpretation. In the author's opinion, the recycling of architecture - reconstruction and conversion - is worthy of special interest, because we are simultaneously pursuing motifs such as preserving the identity of the building, its materiality and ideology, as well as environmental and distinctive motifs arising from both current requirements and the architect's personality. It is the harmonization of the mentioned motifs that is probably the biggest difficulty, due to which much architecture undergoes demolition instead of intervention. It is unthinkable to build sustainable architecture, recycle used materials and waste and at the same time to dispose of buildings that encompass potential values as well as a certain amount of energy. Therefore, it is important to deal with recycling comprehensively, both in architecture and in every creative work, because to create without thinking about what has been created is unsustainable, environmentally as well as culturally and socially.

\section{REFERENCES:}

[1] Meriam Webster Dictionary. [online] Available at: https://www.merriam-webster.com/dictionary/recycling [Accessed: 31 January 2021]

[2] Lovich, P. (2013) "Recyklácia" (Recycling), In: ŠPAČEK, R., PIFKO, H. (eds). Rukovät' udržatel'nej architektúry, SKA,

Bratislava, pp. 112. (in [Slovak])

[3] Lovich, P. (2013) "Recyklácia” (Recycling), Rukovät' udržatel'nej architektúry, SKA, Bratislava, pp. 112. (in [Slovak]) [4] Lovich, P. (2013) "Recyklácia” (Recycling), Rukovät' udržatel'nej architektúry, SKA, Bratislava, pp. 113. (in [Slovak]) [5] Pintos, P. (2020) "Old Brick New House / Wrzeszcz Architekci“, ArchDaily, [online]. Available at:

https://www.ArchDaily.com/935645/old-brick-new-housewrzeszcz-architekci [Accessed: 2 February 2021]

[6] Pintos, P. (2020) "Old Brick New House / Wrzeszcz Architekci”, ArchDaily, [online]. Available at:

https://www.ArchDaily.com/935645/old-brick-new-housewrzeszcz-architekci [Accessed: 2 February 2021] [7] Franco, A. (2020) "8B Nave / Arturo Franco", ArchDaily, [online]. Available at: https://www.ArchDaily.com/445236/8-bnave-arturo-franco [Accessed: 3 February 2021]

[8] Perić, A., Sijaković, M. (2014) "Recycling Architecture The Redefinition of Recycling Principles in the Context of Sustainable Architectural Design", Plan it Smart - Clever Solutions for Smart Cities, CORP, Schwechat, Austria, pp. 467-476. [online]. Available at: https://www.corp.at/archive/CORP2014_16.pdf [Accessed: 1 February 2021] 
[9] Perić, A., Sijaković, M. (2014) "Recycling Architecture:

The Redefinition of Recycling Principles in the Context of Sustainable Architectural Design", Plan it Smart - Clever Solutions for Smart Cities, CORP, Schwechat, Austria, pp. 467-476. [online]. Available at:

https://www.corp.at/archive/CORP2014_16.pdf [Accessed: 1 February 2021]

[10] Jäger, F. P. (2010) "Design Manual for Revitalizing Existing Buildings", Birkhäuser GmbH, Basel, Switzerland, pp. 18178.

[11] Perić, A., Sijaković, M. (2014) "Recycling Architecture: The Redefinition of Recycling Principles in the Context of Sustainable Architectural Design", Plan it Smart - Clever Solutions for Smart Cities, CORP, Schwechat, Austria, pp. 467-476. [online]. Available at:

https://www.corp.at/archive/CORP2014_16.pdf [Accessed: 1 February 2021]

[12] Perić, A., Sijaković, M. (2014) "Recycling Architecture: The Redefinition of Recycling Principles in the Context of Sustainable Architectural Design", Plan it Smart - Clever Solutions for Smart Cities, CORP, Schwechat, Austria, pp. 467-476.

[online]. Available at:

https://www.corp.at/archive/CORP2014_16.pdf [Accessed:

1 February 2021]

[13] Jodidio, P. (2015) “Chipperfield”, Taschen GmbH, Köln, Germany, pp. 14.

[14] Jodidio, P. (2015) "Chipperfield", Taschen GmbH, Köln, Germany, pp. 14.

[15] Moravčíková, H., (2020) "Obnova areálu Múzea Slovenských národných rád” (Renovation of the Slovak National Council Museums), Ročenka slovenskej architektúry 2018/2019, Slovart, Bratislava, Slovakia, pp. 42. (in [SlovakEnglish]) 